\title{
BIM IMPLICATIONS IN THE DESIGN PROCESS AND PROJECT-BASED LEARNING: COMPREHENSIVE INTEGRATION OF BIM IN ARCHITECTURE
}

\author{
CARLOS L. MARCOS \\ University of Alicante, Spain
}

\begin{abstract}
This paper tries to reflect on the advantages and disadvantages of the BIM paradigm in the context of university education, on the one hand, and the way in which its potentialities could benefit architectural teaching, on the other. A comprehensive implementation of the tool within the architectural degree curriculum can enhance students' learning process, taking advantage of the cross-disciplinarity inherent to BIM as well as relying on the project-based learning model, especially suitable in architectural tuition. Truly digital design studios could benefit and be nurtured with the contents of other disciplines such as construction, structures, building service systems or architectural representation. Students could work on the same models during the same academic course across their curricular matters, adding layers of information and detail to the project depending on the subject content's. Besides, collaborative work could also be improved with team work allowing the use of collaborative BIM tools to make the students familiar with the kind of work they will find once they finish their studies.
\end{abstract}

Keywords: BIM, BIMing, 3DD model, architectural curricula, PBL, integrated practice.

\section{INTRODUCTION}

The so called 'digital turn' [1] has brought major changes in architectural design and in the construction industry. Bold designs that were only premonitory a couple of decades ago have now become not only possible but also somewhat trendy in certain circles. Digital design studios have become a regular practice at architecture schools giving way to architectural innovation and making good use of CAD-CAM convergence [2]. Fablabs are also a growing standard in architecture and design schools making possible the digital fabrication of computer designed prototypes. Parametricism and algorithmic architecture have redefined the concept of form in what could be referred to as 'open form' [3], swapping from the material limitations characteristic of any form of architectural representation to geometries defined in topological terms implemented in codes (scripts). Following form finding strategies [4] architects are now able to seek and optimise a design result just by running scripts and taking advantage of the great computational capabilities of computers [5]. All of this could not have been accomplished without the systematic use of ITs applied to architectural design and practice. Nevertheless, most of these architectural trends are designer oriented, that is to say they have been focused on enhancing architectural design itself, thus giving the architect an extraordinary repertoire of digital tools to help him in his design task.

Building Information Modelling (BIMing rather than simply BIM, which could stand solely for the building information model itself as it is proposed in this paper), on the other hand, is also part of the mentioned 'digital turn' but unlike the great majority of the digital tools that have been developed throughout these decades is professionally oriented. The necessary standards that have been promoted with regard to building information modelling (ISO/TC59/SC13, CET TC/442, PAS 1192, etc.) are quite revealing with regard to the construction industry interests as well as those of the CAD software companies.

The combination of a three-dimensional model with a geometric referenced database has had an enormous impact in the way architects may tackle the design problem. The advantages 
are so obvious and the industry's interest so great, that in a relatively short period of time it has progressively become a mandatory standard to work for public clients in many countries (USA, Denmark, Finland, etc. - in Germany it is expected to be set in 2020), something that will undoubtedly happen with private contractors in the near future-large contractors already require this kind of working standard. BIMing has probably bridged the gap between construction and design, between architects' production and the construction process in its entire life cycle. It has modified the way architects design and has questioned the importance given to the abstractive approach based on the 'idea' in the design process, a conception with regard to authorship that could be traced back to Renaissance. However, many collateral questions have been raised as BIMing has become the indispensable tool that every architecture student wants to learn. The changes introduced in the design process through the use of BIMing are worth being analysed to be aware of the new design-construction paradigm that has been established. The following lines try to discuss the implications in the design process introduced by Building Information Modelling and how these may be considered a pedagogical opportunity for the enhancement of architectural tuition and learning processes as much as, if wrongly planned within the curricula, it may entail certain risks [6].

\section{BIM IMPLICATIONS IN THE DESIGN PROCESS}

Building information modelling has significantly changed the way architects and engineers work within the project [7] enhancing cross-disciplinarity. From conception design to life cycle maintenance going through detail design or construction documentation, the building information model has completely altered the relationship of the designer with the object of his design activity. A building information model is a three-dimensional digital model comprising a geometric database, that is to say a three-dimensional data model (3DD model). Although the conception of such digital models can be traced back to the mid-1980s [8], it has only been in the last two decades that they have progressively become a design standard.

The initial technological delay of the construction industry in comparison with the aeronautic or shipbuilding industries regarding the development and implementation of the digital tools to which Kolarevic refers to [9] has progressively been reduced; BIMing is another step further in this gap reduction. The construction industry has a conservative tradition, partially indebted to the fact of historicist and revivalist trends found throughout the history of the discipline as architects have looked back to classicism searching for references of disciplinary authority favoured by institutional clients willing to embody their power. Digital architecture can claim to have superseded these historicist trends, even disregarding modernity as a valid reference; innovation through digital culture in architecture [10] is now unquestioned after the aforementioned initial technological delay.

In addition, the construction industry became aware of the potential of the digital tools to make more efficient project design and construction management some decades ago. When in 1994 Autodesk created the industry consortium Industry Alliance for Interoperability (IAI) the objective was clear, creating software standards to achieve interoperability. Only three years later it became an international initiative being founded as a non-profit industry-led organisation being renamed as the International Alliance for Interoperability (IAI), later to become BuildingSMART. The amount of money this industry moves worldwide is overwhelming; it was only a question of time that the main actors in the industry would try to avoid systematic significant budget deviations in architectural projects, almost a hallmark in the profession especially significant in the design and construction of public buildings everywhere. Building Information Modelling emerged as the logical tool favouring an integrated practice where the different actors involved from the design to the construction 
phases of the project could collaborate [11] providing a certain cost estimate at the initial stages that could be automatically generated through efficient quantity surveying referenced to the geometry and the constructive definition of the model simultaneously.

The question, however, remains on how this professionally oriented shift in software may be implemented into architectural curricula. Many schools have decided to redesign their curricular courses to face this new challenge and opportunity and the initiative is becoming trendy as professionally wise the BIM transformation becomes unstoppable [11]-[14]. However, there is no agreed standard with regard to the way in which this should be achieved. We need to analyse the design implications of this new conception to propose a sensible and purely academic approach which should be neither a compromise between profession and software developers nor an imposition of the construction industry. Our decisions should be taken on a pedagogical basis prioritising the learning process alone but without obviating today's construction industry and the actual professional reality.

Architects do not produce buildings; they used to produce drawings and plans to define how buildings should be constructed. The construction process has traditionally been a kind of translation from a set of codified information contained in abstract orthographic projections into the materialisation of the building itself [15]. That is the reason why architectural representation has been so important since the fifteenth century onwards in architects' learning process and practice. When architectural drawing mastered the use of projections - orthographic and perspective - architects began to use it as the preeminent tool to design architecture thereof becoming a significantly graphical activity and introducing a clear disruption regarding medieval master builders' tradition. Accordingly, architectural drawings have been used ever since not only to convey the architecture to be built but also as the language used to think architecture itself [16].

The composer does not play the music he composes but rather writes it in a score; architects have been drawing plans to design and represent the architecture they conceive for centuries. Goodman in his The Languages of Art refers to the 'notational' character of some of the graphic production featured in architecture plans. Just as music is materialised when the score is played by the musicians of the orchestra and interpreted by the conductor, architecture is built from the plans that are materialised into a construction. Ambrose writes referring to architectural drawings the following: "they are a linguistic system, a visual, graphic language, and as such they are inherently an abstract system of symbolic representation" $[17$, p. 183]. It is quite obvious that these plans entail a great deal of abstraction, on the one side, and constitute a partial representation of the architectural whole, on the other.

CAD software did not change much this architectural tradition until the introduction of the three-dimensional virtual space. Originally, CAD tools were conceived as a digital reinterpretation of drafting just as primitive pen plotters where designed as mechanic draughtsmen. The two-dimensional virtual plane acted as a kind of virtual paper where drawings could be digitally drafted - and endlessly edited - to be plotted when finished into paper plans. The only main difference was the problem of scale which has never been properly addressed by CAD software. When physically drafted, a plan was drawn with the required level of detail in accordance to the scale it was drawn to. The 1 to 1 scale CAD drawing ideal in the virtual space was unreal in as much as the level of detail was always fixed by the draughtsman in the drawing he was producing. It is to be noted that BIM has addressed this problem although it is yet to be perfectioned in future releases.

The conception of a three-dimensional virtual space was probably the first major shift introduced in architectural design by ITs. Unlike drawings a 3D model is a global holistic geometric representation of the designed architecture; therefore, it is not a compendium of 
reductive information based on projections [18] deduced from an envisaged architecture as conceived by the architect. This was certainly a major change in the disciplinary tradition since, despite physical models had always been dealt with, the precision of CAD was now applied to a three-dimensional representation of architecture. In combination with NURBS this possibility favoured architects' potential to design unprecedented geometries, initially blobs and other complex geometries later enriched with the introduction of parametric design.

With the advent of BIMing technologies, architects and designers alike have a much more complex instrument to help them to define their designs, the building information model (BIM): an extraordinary digital avatar that is a replica of the designed architecture with an unprecedented level of accuracy and information. Unlike conventional 3D models, it is not a mere three-dimensional representation of architecture where the information of every element within the model is solely based - at its best - on the visual appearance of its materiality, that is to say a texture, a colour or a particular finish of a specified material oriented to anticipate the visual perception of a building depending on light effects. Building information models are much more than that, they belong to a really different realm. They share the geometric accuracy of digital three dimensional models but the elements that define the architectural model, apart from their geometry, may also have a wide range of geometrically referenced data - using the project's coordinates - that can precisely specify their particular features. For instance, a particular manufacturer, brand and model of a window, its cost, the materiality of its frame, its colour, the design of its profile, the kind of glazing it bears or even its thermal performance, just to mention a few. If we compare this only digital file with the amount of documents that would be needed in a conventional project to achieve the specifications of all those features we can be easily persuaded about the incredible potential of this revolution that architecture is now undergoing through. In terms of architectural learning, a finished BIM can be the support for a wide range of subject contents that students need to learn along their architectural degree courses. Moreover, the enhanced visual display features of the latest versions may serve as a dissection of a building detailed to the nuts and bolts allowing for cross disciplinary approaches.

BIM share with 3D models the precision of managing the entire architectural objects' geometry, to begin with. However, they may add as much data as any element within the entire architectural fabric could need to be thoroughly defined; properly speaking the model is a three-dimensional data model (3DD model). These intelligent objects may include material specifications that may serve, for example, to simulate a particular design's energy performance. The BIM is therefore a representation of the architecture to come but with the capacity to anticipate the building's behaviour based on simulation. It is the combination of both, a three-dimensional representation of architecture and the possibility to associate data to every element in the model, what makes make of BIMing a new design paradigm; a shift based on simulation and information management [19, p. 284].

In addition, the amount of data defined for every element in the building information model is unlimited. As the amount of parameters may be increased the enhanced model is in fact a multi-dimensional container which has three geometric dimensions. Thus, time can also be another dimension or input into the model. This has also altered a certain traditional fossilisation of the project with regard to the built architecture as a finished document. The BIM can either be used to simulate the construction process (4D), or to anticipate and estimate costs in real time including project's changes (5D), or to anticipate the sustainability of the building in terms of energy consumption optimisation (6D), or to plan and monitor the building's maintenance (7D). Students may get a fabulous perspective of the complete lifecycle of a building, from its design conception to the maintenance of the building itself. 
As any digital file, the editability of the model based on its virtuality allows to introduce as many changes as desired, keeping all the information within the project updated at every stage. The semantic nature of the model [13] makes it possible to query the geometrically referenced database to obtain all the information needed. Plans, renderings or project's schedules can also be produced directly from the model; almost a dream come true - as a practitioner, who wouldn't have loved to get the door schedule with all the specifications of a large building at a mouse click? This is in fact one of the major goals of the BIMing spirit: all the information of the project is contained and defined within the model itself; once it is there it can be used along the design process to generate the necessary project's documentation which will be always updated provided the model also is, in accordance with its geometric consistency. This integration is probably the main reason for building information modelling success as the optimisation of time and the reduction of errors are a direct consequence of the informational structure of the whole system.

Moreover, the information contained in the model is not anarchic but hierarchically ordered. This implies a series of very interesting logical constraints within the model beyond the obvious geometric ones. The host-guest relationship of some elements with regard to others (i.e. a wall hosting a window, a complete distribution hosted by a level, etc.) implies a hierarchic definition of the constructive elements conceived in constructive terms. Thus, the information is categorised and ordered according to an established logical hierarchy: categories, families, types, instances, parameters. This feature is also a great opportunity for architectural teaching as students must understand and be aware of the constructive logic behind every design decision. A line in a conventional plan is no more than that, it could either represent an edge, one of the limits of a sectioned wall, or simply be part of a hatch: line weights are used to codify their meaning but, apart from that, they are only lines. In contrast, every element in the building information model must have a constructive sense and be hierarchically assigned to the corresponding family, type or the like.

Building information modelling is a change of paradigm that is unmistakeably client or professionally oriented but it is in fact a whole conception and a complete information system, not simply a tool to define the building information model itself; the importance should therefore be laid on the activity itself rather than on a particular software application [20]. BIMing also introduces a shift in the way cross-disciplinary teams collaborate in the development of the project, introducing new possibilities of information sharing. This also implies an increase in the complexity of information management within the project together with a clear organisation of the work for every party involved. Depending on the complexity of the design the amount of information within the model can be so large that the project may need to be subdivided. Large projects urge the need for a BIM manager, someone who does not necessarily have to be an architect. The success of the project may depend on the way the organisation and structure of the information model is conceived and handled.

Despite the efforts of the Internatonal Alliance for Interoperability (IAI) - now BuildingSMART - to set a compatible standard through the establishment of the so-called Industry Foundation Classes (IFCs) between different software files, this goal remains a clear failure of the building information modelling aspirations. More research is being done and many institutions are working on the standardisation of the BIM conceptual frame and integrated practice. The International Council for Research and Innovation in Building and Construction has published a research roadmap report Integrated Design and Delivery Solutions (IDDS) which is a useful document setting the guidelines for 'the investigation in sustainability, improved practices and better knowledge capture, all well-understood priorities for innovation' [21]. Three imperative conditions are needed to achieve success within the IDDS framework: Collaborative work, integrated process and technologies 
interoperability. BIMing is already quite successful in the management of the first two, remaining the interoperability as the Achilles heel of the whole conception even if some improvements have been made with regard to it. The question is if the issue of interoperability collides with the software industries' interests. This matter is basically dependent on them and considering the early foundation of the IAI consortium and its pretended interest in achieving real interoperability facts don't seem to favour optimistic prospects of the problem.

Moreover, the extraordinarily professional and productive orientation of BIMing has other implications regarding the roles between the different actors involved in the construction industry. To begin with, the design rights may be questionable as more parties get involved and contribute to the design but the ownership of the building information model typically belongs to the client. This raises several issues with regard to the design rights which the layering of information within the model makes difficult to assign. Besides there is an opportunity and a risk in the difficult relation between the contractor and the architect. As Seletsky has pointed out: 'Properly ignored, the results [of BIM] may very well promote construction managers into a lead decision-making role...' [22]; obviously, architects would want to avoid such intrusion in their own role but the tool is so powerful that once it is in the hand of the owner, design changes may be easily introduced, something which clearly entails a professional risk regarding authorship on the architects' side. Although it should be noted that BIM also allows architects to regain lost ground delving themselves back into the knowledge management of a project from its conception till its construction, and beyond; from the concept design to the nuts and bolts of the detail [23].

\section{PROJECT-BASED LEARNING AND INTEGRATED PRACTICE}

All these changes and implications in the design process previously analysed should make us reflect on the need for a change in architectural education in accordance to this new challenge driven by the evolution of IT applied to architectural design. However, since these changes are so profound it seems logical to weigh the way in which this curricular transformation should be addressed. Should the construction industry or the CAD software companies drive this educational change or should academia decide the best way in which to implement this ongoing transformation?

We need to reflect on the pedagogical models that could match BIM requirements from an educational point of view. BIMing is about integrated practice, about cross-disciplinary collaboration in the achievement of a common goal: the architectural design especially oriented to the project delivery. Integrated practice implies the complicity of all actors involved in the design process sharing common information to attain a good collective design result. Architecture is a choral discipline involving many parties even if the need for a plan director - the architect - is still desirable.

Traditionally, architectural education has been based in creativity and abstracting the representation of the architectural design in drawings. This standard is difficult to dismantle as plans have a great efficiency in conveying architectural design; moreover, many design decisions can be better taken in section or in plan rather than in a perspective or in the model itself. The abstraction of the canonic architectural orthographic projections - plan, section and elevation - in which traditional conventions rely are derived from the fact of a world being governed by gravity and all the constructive implications this fact alone entails.

BIM completely changes this visual relationship based on projections and drawings into a 3D informational model which constitutes itself as a formidable avatar with regard to the architecture of which it is a precise replica. Thus, applying the new CAD standard to conventional architectural pedagogy may not suffice. A deep change may be needed without obviating the creative role within the design process [6]. 
Project-based learning (PBL) is a pedagogical model based on learning around projects. Quite differently, the classical "chalk and talk" teaching model is based on the teacher's knowledge and his ability to lecture on the topics of his subject matter driving students to take notes that should be reworked and studied with book reading and on which to be later examined. This pedagogical system relies on memory and on learning to "know" the subject contents. Project-based learning relies on a totally different approach based on learning the "know how", acquiring and developing the skills to deal with problem-solving. PBL "involve the students in design, problem-solving, decision making or investigative activities" giving the students "the opportunity to work relatively autonomously over extended periods of time; and culminate in realistic products or presentations" [24]. Some universities have adopted it with great success in the last decades. Although the beginning of this learning model shift was pioneered in medicine education some engineering schools have adopted it as a central pedagogical reference within their curricular design; probably Aalborg's University in Denmark is one of the best-known examples.

Bloom's [25] famous taxonomy of cognitive skills classifies them into six different categories in accordance with increasing levels of abstraction involved to achieve them: knowledge, comprehension, application, analysis, synthesis and evaluation. Some years later, paying attention to factual skills in the learning process Bloom's taxonomy was revised in 2001 [26] substituting nouns for verbs, adding creativity instead of synthesis and positioning it as the higher cognitive skill thus leaving the categories of the cognitive process dimension as shown in Table 1.

Moreover, Anderson and Krathwohl [26] also added a knowledge dimension which classified different kinds of knowledge, from the more concrete or specific to the more abstract in four different types: factual, conceptual, procedural and metacognitive. It should be noted how in this redefinition of the cognitive skills that students should attain these are displaced from the 'know' to the 'know how' paradigm, on the one hand, and how creativity is now credited as the highest level in the cognitive process, something which should be very important in architectural education and should be especially taken into account when programming the architectural curricula integrating Building Information Modelling in them.

It is obvious that the PBL model is especially suitable for those studies which are focused in the teaching of a profession, typically those that generate productive activity. Architecture and engineering have always relied on PBL even before such learning model was conceptualised and analysed by pedagogical researchers. The work of engineers and architects alike is oriented to design, and every design is borne out of a project. In architecture schools the design studio has worked as the backbone of the entire curriculum for decades. Traditionally, architecture students were taught great drafting skills during the first courses where they learned to codify and became familiar with the use of drawings as the natural language of architecture itself: the scores of the future built work. Obviously, they began to acquire these skills through the representation of exemplary architecture designed by others gradually growing conscious of what architecture was about. Architectural history, aesthetics and other theoretical subjects exposed students to a millenary rich disciplinary tradition progressively introducing them into the theoretical architectural debate and criticism. Technological subjects enriched their tuition regarding construction, structural or building installations. However, all this theoretical tuition, has always been oriented to architectural design as the core subject of the entire curriculum. Projects developed in the design studio gather all this dispersed knowledge to integrate into a single project, this primacy of the subject should remain so independently of the tools used to develop it; obviously that also includes BIMing. 
Table 1: Cognitive process dimension. Categories and cognitive processes (adapted from Anderson and Krathwohl, 2001. (Source: CELT Iowa State University.)

\begin{tabular}{|c|c|c|c|c|c|}
\hline \multicolumn{6}{|c|}{ (Increased order thinking skills to the right) } \\
\hline Remember & Understand & Apply & Analyse & Evaluate & Create \\
\hline $\begin{array}{l}\text { Recognizing } \\
\text { (identifying) }\end{array}$ & \begin{tabular}{|l} 
Interpreting \\
(clarifying, \\
paraphrasing, \\
representing, \\
translating)
\end{tabular} & $\begin{array}{l}\text { Executing } \\
\text { (carrying out) }\end{array}$ & \begin{tabular}{|l|} 
Differentiating \\
(discriminating, \\
distinguishing, \\
focusing, selecting)
\end{tabular} & \begin{tabular}{|l} 
Checking \\
(coordinating, \\
detecting, \\
monitoring, \\
testing)
\end{tabular} & $\begin{array}{l}\text { Generating } \\
\text { (hypothesizing) }\end{array}$ \\
\hline \multirow[t]{6}{*}{$\begin{array}{l}\text { Recalling } \\
\text { (retrieving) }\end{array}$} & $\begin{array}{l}\text { Exemplifying } \\
\text { (illustrating, } \\
\text { instantiating) }\end{array}$ & \begin{tabular}{|l} 
Implementing \\
(using)
\end{tabular} & $\begin{array}{l}\text { Organizing } \\
\text { (finding, } \\
\text { coherence, } \\
\text { integrating, } \\
\text { outlining, parsing, } \\
\text { structuring) }\end{array}$ & $\begin{array}{l}\text { Critiquing } \\
\text { (judging) }\end{array}$ & $\begin{array}{l}\text { Planning } \\
\text { (designing) }\end{array}$ \\
\hline & $\begin{array}{l}\text { Classifying } \\
\text { (categorizing, } \\
\text { subsuming) }\end{array}$ & & $\begin{array}{l}\text { Attributing } \\
\text { (deconstructing) }\end{array}$ & & $\begin{array}{l}\text { Producing } \\
\text { (construct) }\end{array}$ \\
\hline & $\begin{array}{l}\text { Summarizing } \\
\text { (abstracting, } \\
\text { generalizing) }\end{array}$ & & & & \\
\hline & $\begin{array}{l}\text { Inferring } \\
\text { (concluding, } \\
\text { extrapolating, } \\
\text { interpolating, } \\
\text { predicting) }\end{array}$ & & & & \\
\hline & $\begin{array}{l}\text { Comparing } \\
\text { (contrasting, } \\
\text { mapping, } \\
\text { matching) }\end{array}$ & & & & \\
\hline & $\begin{array}{l}\text { Explaining } \\
\text { (constructing } \\
\text { models) }\end{array}$ & & & & \\
\hline
\end{tabular}

If we take a look at all the cognitive skills listed in Table 1 the first four main categories (remembering, understanding, applying and analysing) can be achieved in most of the theoretical subjects, always having a given architecture as a referent. Partially, evaluating could also be attained in some of these courses. Architectural representation can traverse most of the categories due to its propaedeutic nature and furthermore because traditionally an extremely thin line has defined the limit between drawing and designing. However, solely creating - the base of any architectural design - may be regarded as a clear-cut category associated with architectural design within the curricula. This fact has to be well understood in order to proceed intelligently in the integration of the BIM standards in the architecture curriculum.

\section{BIM AS A WORKING STANDARD IN ARCHITECTURE SCHOOLS}

Having thoroughly analysed the implications of the BIM tool within the design process together with the required learning model based on PBL and integrated practice and the cognitive skills needed in architectural education we find ourselves in the position of 
proposing some curriculum design strategies and recommendations to integrate building information modelling.

This research is triggered by the willingness of part of the teaching staff at Alicante's University who are striving to integrate BIM within our architecture curriculum. In 2016, the University of Alicante signed a strategic agreement with Autodesk; since then several BIM related courses at different levels have been taken indistinctly by students and staff. These reflections try to shed some light with regard to the opportunity ahead of us aiming to a sensible integration of BIM as a working standard in the near future at our Architecture School.

Although BIMing has been going on for decades - Archicad's first release is dated in 1984 (it was then called Radar $\mathrm{CH}$ ) - it has only been in the last one that it has become a professional working standard. The advantages are so considerable that it has become a working standard in the construction industry outpacing architecture schools just as happened with the emergence of the first CAD tools. The significant level of complexity of the digital shift introduced by building information modelling and the speed of the changes within the software industries are followed with difficulty by academia. Thus, many schools have tried to integrate building information modelling finding a certain opposition on some sectors of the teaching staff, some of which prefer to comfortably maintain their status based on their position and knowledge which may no longer be as important as it used to and for whom digital tools such as BIMing are quite alien. On the other hand, there is not a single possible approach for 'designing and implementing BIM curricula because each academic program is different with its unique approach to BIM interpretations and practices' [13]. Architecture schools will have to deal with this issue sooner or later. Students are already aware of the tool's potentials and what is most important: they are completely conscious of the demand of BIM skills in the architecture labour market. Accordingly, they are beginning to demand such tuition within their curriculum.

Cheng [27] has warned on the difficulties and risks of applying BIM without changing the pedagogical model [6] thus, if BIM is carelessly introduced within the architecture curriculum design thinking and its central role in architectural learning could be overshadowed. BIM has a great potential to help the students attain a good amount of the cognitive skills redefined by Krathwohl in 2001; it looks quite evident that at least the first four (remembering, understanding, applying and analysing) could easily been achieved or enhanced through the use of building information models. That includes the contents of most of the theoretical technological subjects, and obviously also all the representational issues with the potential graphic output of drawings and plans rendered from the model itself. All the simulation of which the BIM is capable of in terms of energy consumption or structural analysis is also enhancing the students' evaluation skills.

However, creativity is probably the only skill which may be neglected by a BIM approach. The fact that any design is progressively developed throughout the design process and that at the early stages the architectural 'idea' or the conceptual approach may be vaguely defined may not be easily tackled through the construction of a BIM model which is probably more suitable once an overall idea is reached which needs to be fixed to the necessary dimensional limitations of site and program. It is true that conceptual masses and generic families are software enhancements to try to save this gap but, even if their potential is still to be enriched as the modelling capabilities of the conceptual masses are improved in future versions of the BIM programs, the constructive approach tend to think of the tool as more suitable for more developed stages of the project. After all BIM tools are production and optimisation oriented [28], not necessarily design thinking focused. 
The extraordinary possibilities of the BIM model as a teaching tool have been explored by Ambrose in a kind of reverse engineering process [6] at the University of Maryland. A given finished BIM model is used to show the students the potential of the tool and how the different parties involved have developed and solved their components within the model. The real practitioners who have developed the model explain how they dealt with the different design problems faced across-disciplines. In a second phase students are asked to change a fundamental system of the given model such as the structure to propose a different structural system and solve the dimensional requirements and other design implications that such a change entails alone; this phase is developed on a collaborative team basis. During the last phase students are required to individually change the entire curtain wall system to end up digitally fabricating a prototype to test the constructability of one component of this curtain wall system. This teaching practice exemplifies a way to implement BIM technologies within the curricular design. It includes a PBL approach including collaborative as well as individual working and the process itself is progressively immersed in the complexity of the BIM working system. However, the lack of a global design task - a whole building regardless of its scale - undermine the creative capacity of the students at the design studio. Productivity and not form configuration is at the very base of BIMing, thus weakening the creative approach.

It is quite evident that BIM can be a really powerful tool with regard to technical construction and material specifications. The construction of a 3DD model implies a detailed conception of the building elements and components involved in a given design. Thus, other examples of this focus have been reported by Cory and Schmelter-Morret [29] who implemented a BIM course specifically conceived for the construction discipline; the course focused on the technical implementation and data flows through the interaction of the architectural, structural and MEP models in a real-world building project. BIM is very suitable for this kind of specific approach be it either through the use of readymade BIM models on which to work on - as in the studio developed by Ambrose - or models to be developed specifically for a constructive purpose. The knowledge skills here would include most of the six categories although, once again, a partial approach with regard to a particular constructive system will not favour the holistic understanding of the architectural design.

Kensek surveyed three different level courses in the University of South California, General integration of BIM technologies - getting to know the software and the working BIM standards, Advanced BIM-related topics - more advanced BIM related topics such as performance base design, and Professional engagement - intended to facilitate the involvement of the students with the profession through industry-focused workshops and conferences [30].

Probably an ideal immersion into BIM technologies would be favoured if students were progressively taught from the beginning of their studies commencing with building the models and getting to know how to use the software on a representational basis - with little constructive detail - of exemplary works of architecture which could serve them as part of their disciplinary tuition. That would be equivalent to architectural representation but working on a 3D model root from which to obtain plans and renderings. Later on, these models could be partially developed in the different technical subjects adding layers of information and detail to the model to teach students about the benefits of a three-dimensional information model. These subjects should also use readymade BIM complex models to show students the work in a real model with all the complexity it entails with real constructive solutions. From second year onwards the students would be asked to develop their own projects at a design studio to make sure creative skills are attained. These designs could simultaneously be backed by technical subjects adding levels of constructive, structural or 
MEP detailing. The accuracy and level of definition of the model could be analysed to test the success of their learning process [13]. The BIMing approach could be worked individually in the second year and could involve collaborative design making use of BIM server technologies to promote interaction across disciplines and collaborative work among teams of students that would have to specialise to work on the same project during the last degree courses. A PBL fully integrated throughout the curriculum could use the potential of the architectural design subjects as catalysts for a real integrated practice across disciplines and the PBL learning model structured in the design studio as the core of the learning process. Every discipline would pivot around this backbone and students would progressively be immersed into more detailed constructive and structural problems solved through the use of BIM as the learning process advanced and the level of detail involved increases as their disciplinary knowledge grows.

\section{CONCLUSIONS}

Integrating BIM into architectural curricula is a great opportunity to enhance students learning process. It is consistent with professional trends and it has an enormous potential in helping to attain the desirable cognitive skills. Most of the subjects can use BIM as a design - promoting students' use of BIM in their design studio work, and as a study tool - analysing and working with readymade complex or purpose oriented BIM models. BIMing is more difficult to implement in History and Design theory subjects. Creativity as the higher cognition skill and the main goal of architecture education should not be undermined with the use of the tool; for instance, through careless repetition of off-the-shelf library predefined families and types. The tool is great in the representational aspect as it is in the technical architectural cross disciplines; not so much in the creative facets. Architecture curricula could be significantly enhanced through the consistent and comprehensive integration of Building Information Modelling throughout the different courses of the degree provided it is based on the 'know how', 'PBL' and 'collaborative work' pedagogical framing leaving architectural design as the core of the learning process adding layers of definition, detail and specificity to the proposals made at digitally conscious integrated design studios.

\section{ACKNOWLEDGEMENTS}

This paper partially shows the results of the research project "Pensamiento Gráfico. Estrategia de Proyecto y Lenguaje Arquitectónico" funded by the University of Alicante, evaluated by the ANEP and obtained in a public competition.

\section{REFERENCES}

[1] Carpo, M., The Digital Turn, John Wiley \& Sons Inc: New York, 2012.

[2] Kolarevic, B., Information master builders. Architecture in the Digital Age: Design and Manufacturing, ed. B. Kolarevic, Taylor \& Francis: Abingdon, UK, 2003.

[3] Marcos, C., Complexity, digital consciousness and open form: A new design paradigm, LIFE in:formation, On Responsive Information and Variations in Architecture, Proceedings of the Acadia 2010 Conference, New York, pp. 81-87, 2010.

[4] Leach, N., Digital morphogenesis. Architectural Design, 79(I), p. 34, 2009.

[5] Terzidis, K., Algorithmic Architecture, Architectural Press: Oxford, p. xii, 2006.

[6] Ambrose, M.A., BIM and integrated practice as provocateurs of design education, CAADRIA 2007 Conference Proceedings, Nanjing, pp. 283-288, 2007.

[7] Harty, J., Kouider, T. \& Paterson, G., Getting the Grips with BIM, Routledge: New York, 2016. 
124 Building Information Modelling (BIM) in Design, Construction and Operations II

[8] Aish, R., Building modelling: The key to integrated construction cad, CIB 5th International Symposium on the Use of Computers for Environmental Engineering related to Building, 1986.

[9] Kolarevic, B., Introduction. Architecture in the Digital Age: Design and Manufacturing, ed. B. Kolarevic, Taylor \& Francis: Abingdon, UK, 2003.

[10] Picon, A., Digital Culture in Architecture, Birkhäuser: Basel, 2010.

[11] Ambrose, M.A., Re:thinking BIM in the design studio. Beyond tools...approaching ways of thinking, ASCAAD 2012 Conference Proceedings, pp. 71-80, 2012.

[12] Gu, N. \& de Vries, B., Two approaches to implementing BIM in architectural curricula, Digital Physicallity. eCAADe 2012 Conference Proceedings, Prague, Vol. I, pp. 39-48, 2012.

[13] Dieckmann, A. \& Russell, P., The truth is in the model utilizing model checking to rate learning success in BIM software courses, eCAADe 2014 Conference Proceedings, Newcastle, pp. 417-426, 2014.

[14] Ibrahim, M., Krawczyk, R. \& Schipporeit, G., Two approaches to BIM: A comparative study, eCAADe 2004 Conference Proceedings, Copenhagen, pp. 610-616.

[15] Evans, R., Translations from Drawing to Building and Other Essays, MIT Press: Cambridge, MA, 1997.

[16] Raposo, J.F., Identificación de los procesos gráficos del 'dibujar' y del 'proyectar' arquitectónico, como procesos metodológicos de investigación científica arquitectónica. EGA, Revista de Expresión Gráfica Arquitectónica, (15), pp. 102-111, 2010.

[17] Ambrose, M.A., Plan is dead: To BIM, or not to BIM, that is the question, ASCAAD 2006 Conference Proceedings, pp. 182-189 (p. 183), 2006.

[18] Allen, S., Practice. Architecture, Technique and Representation, Routledge: New York, 2009.

[19] Ambrose, M.A., BIM and integrated practice as provocateurs of design education, CADRIA 2007 Conference Proceedings, Nanjing, pp. 283-288, 2007.

[20] Eastman, C. et al., BIM Handbook: A Guide to Building Information Modeling for Owners, Managers, Designers, Engineers, and Contractors, Wiley \& Sons: New Jersey, 2008.

[21] Owen, R., Research Roadmap Report CIB Integrated Design and Delivery Solutions (IDDS), CIB Publication 370, International Council for Building, 2013. http://site.cibworld.nl/dl/publications/pub 370.pdf. Accessed on: 5 Feb. 2017.

[22] Seletsky, P., Digital design and the age of building simulation. AECbyte, Viewpoint \#19, Nov. 2005. http://academics.triton.edu/faculty/fheitzman/Digital\%20Design\%20 and $\% 20$ the $\% 20$ Age $\% 20$ of $\% 20$ Building\%20Simulation.pdf. Accessed on: 31 Mar. 2017.

[23] Zigo, T., Beyond BIM. The Hidden Potential of the Cumulative Knowledge Factor, Hagerman \& Company, Inc. Technology Bulletin [online], 34 (AEC2). http://newsletters.hagerman.com/newsletters/ebul34-AEC2.html

[24] Thomas, J.H., A Review of Research on Project-Based Learning. http://www.autodesk.com/foundation. Accessed on: 20 Feb. 2017.

[25] Bloom, B.S. (ed.), Taxonomy of Educational Objectives. The Classification of Educational Goals: Handbook I, Cognitive Domain, Longmans Green: Toronto, 1956.

[26] Anderson, L.W. \& Krathwohl, D.R. (eds), A Taxonomy for Learning, Teaching, and Assessing: A Revision of Bloom's Taxonomy of Educational Objectives, Allyn \& Bacon: Boston, MA, 2001. 
[27] Cheng, R., Suggestions for an Integrative Education. American Institute of Architects: Report on Integrated Practice eds M. Broshar, N. Strong, \& D.S. Friedman, The American Institute of Architects. Section: Washington, DC, 5, pp. 1-10, 2006.

[28] Ibrahim, M.M., Teaching BIM, what is missing? The challenge of integrating BIM based CAD in today's architectural curricula. Em 'body'ing Virtual Architecture 2007 ASCAAD Conference Proceedings, Alexandria, pp. 651, 660, 2007.

[29] Cory, C. \& Schmelter-Morret, S., Applying BIM in design curriculum. Computational Design Methods and Technologies: Applications in CAD, CAM and CAE Education, eds N. Gu \& X. Wang, IGI-Global, PA, pp. 122-138, 2012.

[30] Kensek, K.M., Advancing BIM in academia: Explorations in curricular integration. Computational Design Methods and Technologies: Applications in CAD, CAM and CAE Education, eds N. Gu \& X. Wang, IGI-Global, PA, pp. 101-121, 2012. 